\title{
Níveis de energia metabolizável em rações de ovinos Santa Inês: peso dos órgãos internos e do trato digestório
}

\author{
Metabolizable energy levels in the rations of Santa Ines sheep: \\ weight of internal organs and digestive tract
}

\author{
Rildson Melo Fontenele ${ }^{1}$; Elzânia Sales Pereira ${ }^{2 *}$; Patrícia Guimarães Pimentel ${ }^{3}$; \\ Ivone Yurika Mizubuti ${ }^{4}$; Antônia Lucivânia de Sousa Montes; Magno José Duarte \\ Candido ${ }^{6}$; José Gilson Louzada Regadas Filho7 ; José Nery Rocha Junior ${ }^{8}$
}

\section{Resumo}

Avaliou-se o efeito de diferentes níveis de energia metabolizável nas rações sobre o peso dos órgãos internos, compartimentos gastrintestinais e conteúdo do trato gastrointestinal (CTGI) de ovinos em crescimento. Foram utilizados 20 ovinos Santa Inês em crescimento, com idade e peso corporal médio de 50 dias e $13,00 \mathrm{~kg}$, respectivamente. Os animais foram distribuídos em quatro tratamentos experimentais com diferentes níveis de energia metabolizável (2,08; 2,28; 2,47 e 2,69 Mcal de EM/ kgMS), em delineamento em blocos casualizados, com cinco repetições. Não foi observada influência dos níveis de energia metabolizável (EM) sobre os pesos do coração, pulmões e CTGI, expressos em $\mathrm{kg}$ e $\%$, assim como rins e baço, expressos em \%. Houve aumento linear para os pesos, em $\mathrm{kg} \mathrm{e} \%$, do fígado. Detectou-se, efeito quadrático e linear para os pesos, em $\mathrm{kg}$, dos rins e baço, respectivamente. Entretanto, não foi observada influência dos níveis energéticos das rações experimentais sobre os pesos, em $\mathrm{kg}$, do rúmen-retículo e omaso bem como para o abomaso, em $\mathrm{kg}$ e \%, e para o intestino delgado, expresso em \%. Já para o peso do rúmen-retículo e omaso, expressos em \%, observou-se decréscimo linear, do peso desses órgãos, com o aumento dos níveis de energia metabolizável. O peso do intestino delgado, em kg, foi influenciado positivamente em função dos níveis de EM das rações experimentais. Para os pesos, em kg e \%, do intestino grosso, foi observado efeito linear e quadrático, respectivamente, à medida que aumentava-se os níveis de EM nas rações experimentais. Neste estudo, foi observado efeito significativo para os pesos, em $\mathrm{kg}$ e \%, das gorduras perirenal, mesentérica e do coração. $\mathrm{O}$ aumento dos níveis de energia metabolizável das rações influencia o peso dos órgãos internos de ovinos Santa Inês em crescimento.

Palavras-chave: Concentrado, conteúdo gastrintestinal, pequenos ruminantes

\footnotetext{
1 Doutorando do Programa de Pós-Graduação em Zootecnia da Universidade Federal do Ceará, UFC. E-mail: rildsonfontenele@ gmail.com

2 Professora do Departamento de Zootecnia da Universidade Federal do Ceará, UFC, bolsista de produtividade do CNPq. E-mail: elzania@hotmail.com

3 Bolsista PRODOC/CAPES do Departamento de Zootecnia da Universidade Federal do Ceará, UFC. E-mail: pgpimentel@, hotmail.com

4 Professora do Departamento de Zootecnia da Universidade Estadual de Londrina, UEL. Bolsista de Produtividade do CNPq. E-mail:mizubuti@uel.br

5 Professora do Instituto Federal de Educação, Ciência e Tecnologia do Ceará, Campus de Limoeiro do Norte, IFCE. E-mail: lucymonte@uol.com.br

6 Professor do Departamento de Zootecnia da Universidade Federal do Ceará, UFC. E-mail: elzania@hotmail.com

7 Doutorando do Departamento de Zootecnia da Universidade Federal de Viçosa, UFV. E-mail: gilsonagro@yahoo.com.br

8 Graduando em Zootecnia da Universidade Federal do Ceará, UFC. Bolsista de Iniciação Científica do CNPq. E-mail: junior. nery@hotmail.com

* Autor para correspondência
} 


\begin{abstract}
It was evaluated the effect of different levels of metabolizable energy in the rations on the weight of internal organs, gastrointestinal compartments and content of the gastrointestinal tract (CGT) of growing sheep. Twenty growing Santa Ines sheep were used, with age and body weight of 50 days and $13.00 \mathrm{~kg}$, respectively. The animals were allotted into four experimental treatments with different levels of metabolizable energy $(2.08,2.28,2.47$ and $2.69 \mathrm{Mcal} / \mathrm{kgDM})$ in a randomized block design with five replications. There was no influence of the metabolizable energy (ME) levels on the weights of the heart, lungs and CGT, expressed in $\mathrm{kg}$ and \%, as well as kidney and spleen, expressed in \%. There was linear increase for the weights in $\mathrm{kg}$ and $\%$ of the liver. Quadratic and linear effects were observed for the weights, in $\mathrm{kg}$, of kidneys and spleen, respectively. However, there was no influence of the energy levels of experimental rations on weight, in $\mathrm{kg}$, of rumen-reticulum and omasum as well as to the abomasum, in $\mathrm{kg}$ and $\%$, and to the small intestine, expressed in \%. As for the weight of the rumen-reticulum and omasum, expressed in \%, it was observed linear decrease, of the weight of these organs, with increased levels of ME. The weight of the small intestine, in $\mathrm{kg}$, was positively influenced depending on the levels of $\mathrm{ME}$ of the experimental diets. As for the weight, in $\mathrm{kg}$ and $\%$, of the large intestine, it was observed linear and quadratic increases, respectively, with the levels of ME in the experimental rations. In this study, no significant effect was observed for the weights, in $\mathrm{kg}$ and \%, of the pelvic, mesenteric and heart fats. Increased levels of metabolizable energy of the rations influences the weight of internal organs of growing Santa Inês sheep.
\end{abstract}

Key words: Concentrate, gastrintestinal content, small ruminants

\section{Introdução}

Em estudos de exigências energéticas dos animais, a determinação do tamanho relativo dos órgãos internos éimportante, já que diferenças nas partes não integrantes da carcaça podem induzir variações nos requisitos energéticos para mantença. Variações na mantença e eficiência do ganho são freqüentemente mais associadas com o peso e atividade metabólica de órgãos viscerais, como intestino e fígado. Os tecidos viscerais consomem cerca de $50 \%$ da energia destinada para mantença, enquanto os músculos, embora apresentem maior massa no corpo vazio dos animais, consomem $23 \%$ do total da energia para mantença, quando confinados. Isto porque tecidos associados com digestão e metabolismo, como o tratogastrointestinal e o fígado, têm maior turnover proteico que o músculo esquelético. (OWENS; DUBESKI; HANSON, 1993).

Ressalta-se ainda que os componentes nãocarcaça não estão relacionados apenas ao rendimento de carcaça, mas também em alternativa alimentar de populações menos favorecidas, as quais necessitam, invariavelmente, de proteína de origem animal. A obtenção de informação sobre os componentes não-carcaça pode agregar maior valor econômico ao animal e, conseqüentemente, motivar maiores cuidados com o rebanho, possibilitando que o animal expresse seu potencial genético (ROSA et al., 2002).

A gordura pode ser considerada, uma fração importante, como constituinte da carcaça, pois influencia o aspecto visual, a porção comestível e a qualidade da carne, além de servir como proteção (gordura subcutânea) contra a desidratação no resfriamento das carcaças (MOLETTA; RESTLE, 1996). Contudo, o seu excesso pode diminuir o rendimento de carne magra. Porém, o rendimento de carcaça, também pode ser influenciado pelo peso do conteúdo gastrintestinal, que por sua vez é diretamente influenciado pelos números de horas de jejum a que os animais foram submetidos, e pelo tipo de dieta (PATTERSON et al., 1998). O peso do conteúdo do trato gastrintestinal em relação ao peso do corpo vazio é alto em ovinos criados no Brasil, isto se deve basicamente a dois fatores: o primeiro está relacionado com a baixa digestibilidade da fração fibrosa das forrageiras utilizadas em sistemas de pastejo e/ou alta relação volumoso:concentrado. 
Segundo o ARC (1980), o conteúdo do trato gastrintestinal dos animais apenas pode ser mesurado após seu abate, sendo determinado diretamente por pesagem ou, indiretamente, como a diferença entre o peso corporal (PC) e o peso do corpo vazio (PCVZ). Porém, poucas pesquisas têm sido feitas por parte dos nutricionistas de ruminantes sobre os aspectos quantitativos das partes não-integrantes da carcaça, pois estas tendem a variar de acordo com a raça, o estádio de maturidade e o nível nutricional, tendo, conseqüentemente, influência sobre o rendimento de carcaça, as exigências de mantença e o ganho de peso (SIGNORETTI et al., 1999).

Desta forma, objetivou-se com o presente estudo avaliar o efeito de crescentes níveis energéticos (2,08; 2,28; 2,47 e 2,69Mcal de EM/kg de MS), sobre o conteúdo do TGI e peso dos órgãos internos e compartimentos gastrintestinais em ovinos Santa Inês.

\section{Material e Métodos}

O experimento foi desenvolvido no Setor de Ovinocaprinocultura do Departamento de Zootecnia da Universidade Federal do Ceará.

Foram utilizados 20 cordeiros da raça Santa Inês, não-castrados, com peso corporal (PC) médio inicial de $13,0 \mathrm{~kg} \pm 0,56 \mathrm{~kg}$ e, aproximadamente, 50 dias de idade, confinados em baias individuais com piso de concreto e providas de comedouro e bebedouro. Inicialmente, os animais foram pesados, identificados e tratados contra ecto e endoparasitas, posteriormente distribuídos em quatro tratamentos experimentais com diferentes níveis de energia metabolizável (2,08; 2,28; 2,47 e 2,69 Mcal de EM/ $\mathrm{kg}$ de MS), em delineamento em blocos casualizados, com cinco repetições. O volumoso utilizado foi o feno de capim Tifton 85. As rações experimentais foram formuladas conforme o NRC (1985). As rações foram fornecidas à vontade, uma vez ao dia, às sete horas da manhã, e ajustadas de forma a permitir sobras em torno de $20 \%$ do fornecido, com água permanentemente à disposição dos animais.

A quantidade de ração oferecida foi registrada diariamente e, semanalmente, foram coletadas amostras dos concentrados, feno e das sobras por animal para mensuração do consumo de nutrientes, as quais no final do período experimental formaram-se amostra composta/tratamento/animal. Posteriormente, foram pré-secadas em estufa ventilada a $55^{\circ} \mathrm{C}$ e moídas em moinho tipo Willey com peneira de malha de $1 \mathrm{~mm}$, para posteriores análises laboratoriais.

Os ingredientes, rações concentradas, feno e sobras foram submetidos às análises de matéria seca (MS), matéria mineral (MM), proteína bruta (PB) e extrato etéreo (EE), conforme os procedimentos recomendados pela AOAC (1990). As análises de fibra em detergente neutro (FDN) e ácido (FDA), nitrogênio insolúvel em detergente neutro (NIDN), nitrogênio insolúvel em detergente ácido (NIDA) foram realizadas segundo Van Soest, Robertson e Lewis (1991) e lignina (ácido sulfúrico 72\%) foi obtido pelo método seqüencial de Van Soest e Robertson (1980). Os teores de carboidratos totais (CHOT) foram obtidos conforme Sniffen et al. (1992) e os carboidratos não fibrosos (CNF) segundo a equação proposta por Weiss (1999): \%CHOT = $100-(\% \mathrm{~PB}+\% \mathrm{EE}+\%$ Cinzas $)$ e $\% \mathrm{CNF}=100$ $-(\%$ FDNcp $+\% \mathrm{~PB}+\% \mathrm{EE}+\%$ cinzas $)$. Para os concentrados, devido à presença de uréia em sua constituição, o teor de CNF foi calculado conforme proposto por Hall (2000), sendo CNF $=100-[(\% \mathrm{~PB}$ $-\% \mathrm{~PB}$ derivado da uréia $+\%$ da uréia $)+\% \mathrm{FDNcp}$ $+\% \mathrm{EE}+\%$ cinzas].

A composição percentual dos ingredientes e químico-bromatológica dos concentrados e do feno, assim como, a das rações experimentais, são apresentadas nas Tabelas 1 e 2, respectivamente. 
Tabela 1. Composição bromatológica dos ingredientes em \% MS.

\begin{tabular}{lccccccc}
\hline \multicolumn{1}{c}{ Nutrientes } & Feno & Milho & Soja & Conc. 1 & Conc. 2 & Conc. 3 & Conc. 4 \\
\hline Matéria seca & 92,73 & 91,44 & 92,54 & 90,30 & 90,18 & 90,94 & 90,30 \\
Matéria mineral & 6,03 & 1,74 & 6,84 & 3,53 & 3,76 & 3,56 & 3,71 \\
Proteína bruta & 9,94 & 9,39 & 44,05 & 21,14 & 21,72 & 22,00 & 22,27 \\
Extrato etéreo & 0,84 & 5,36 & 4,13 & 3,60 & 4,30 & 5,00 & 4,26 \\
Fibra em detergente neutro & 75,03 & 14,78 & 15,78 & 15,91 & 15,15 & 16,01 & 14,87 \\
Fibra em detergente ácido & 36,32 & 4,78 & 9,24 & 5,63 & 5,67 & 2,70 & 5,83 \\
FDN $_{\text {CP }}$ & 67,91 & 12,76 & 13,74 & 14,16 & 13,72 & 14,61 & 13,45 \\
Carboidratos totais & 83,19 & 83,51 & 44,98 & 71,73 & 70,23 & 69,43 & 69,75 \\
Carboidratos não-fibrosos & 15,28 & 70,75 & 31,24 & 59,16 & 58,64 & 57,03 & 58,56 \\
\hline
\end{tabular}

Tabela 2. Composição percentual e bromatológica das rações experimentais.

\begin{tabular}{|c|c|c|c|c|}
\hline \multirow[b]{2}{*}{ Composição percentual (\%MN) } & \multicolumn{4}{|c|}{ Concentração de EM (Mcal/kg MS) } \\
\hline & 2,08 & 2,28 & 2,47 & 2,69 \\
\hline Feno de teflon & 75,00 & 62,50 & 50,00 & 37,50 \\
\hline Concentrado & 25,00 & 37,50 & 50,00 & 62,50 \\
\hline Fubá de milho' & 77,90 & 77,60 & 77,40 & 77,39 \\
\hline Farelo de soja' & 20,00 & 20,00 & 20,20 & 20,00 \\
\hline Uréia' & 0,88 & 1,18 & 1,22 & 1,25 \\
\hline Calcário $^{1}$ & 0,00 & 0,26 & 0,31 & 0,62 \\
\hline Fosfato bicálcico ${ }^{1}$ & 0,26 & 0,26 & 0,26 & 0,26 \\
\hline Cloreto de sódio' & 0,88 & 0,62 & 0,44 & 0,35 \\
\hline Premix mineral ${ }^{1,2}$ & 0,06 & 0,04 & 0,13 & 0,13 \\
\hline \multicolumn{5}{|l|}{ Composição bromatológica (\%MS) } \\
\hline Matéria seca & 92,12 & 91,77 & 91,83 & 91,21 \\
\hline Matéria mineral & 5,40 & 5,18 & 4,80 & 4,58 \\
\hline Proteína bruta & 12,74 & 14,36 & 15,97 & 17,65 \\
\hline Extrato etéreo & 1,53 & 2,13 & 2,92 & 2,98 \\
\hline Fibra em detergente neutro & 60,25 & 52,57 & 45,52 & 37,43 \\
\hline Fibra em detergente ácido & 28,64 & 24,82 & 19,51 & 17,26 \\
\hline $\mathrm{FDN}_{\mathrm{CP}}$ & 54,47 & 47,59 & 41,26 & 33,87 \\
\hline Carboidratos totais & 80,33 & 78,33 & 76,31 & 74,79 \\
\hline Carboidratos não-fibrosos & 26,25 & 31,54 & 36,16 & 42,33 \\
\hline Nutrientes digestíveis totais & 57,41 & 63,11 & 68,38 & 74,51 \\
\hline
\end{tabular}

'Composição centesimal em relação à porção concentrada da dieta.

A duração do experimento foi definida pelo tempo necessário para que a média do peso de todos os animais de cada tratamento alcançasse 28 $\mathrm{kg}$, ocasião em que os mesmos foram abatidos. Os animais foram pesados ao início do experimento e a cada sete dias, durante o período experimental.
Também ocorreram pesagens intermediárias, quando o peso corporal (PC) dos animais se aproximava do peso determinado para o abate.

À medida que os animais de cada tratamento foram abatidos, escolhia-se aleatoriamente um 
animal que estava recebendo a ração com 2,08 Mcal de EM/kg de MS (animal referência), para ser abatido. Os componentes não-carcaça foram constituídos por rúmen-retículo, omaso, abomaso, gorduras perirenal, omental, mesentérica e do coração, intestinos delgado e grosso, bexiga, aparelho reprodutor e patas. Os componentes do trato gastrintestinal (TGI) foram pesados cheios e, logo após, esvaziados, lavados e novamente pesados, para determinação do conteúdo do TGI. Em seguida, comparavam-se os pesos desses componentes e do conteúdo do TGI dos animais do tratamento que alcançavam peso médio de $28 \mathrm{~kg}$, com aqueles do animal referência, para avaliação da influência dos níveis de energia metabolizável sobre seus respectivos pesos.

As variáveis experimentais foram submetidas à análise de variância e regressão utilizando-se o Sistema de Análises Estatísticas e Genéticas SAEG (UFV, 2007).

\section{Resultados e Discussão}

Não foi observada influência $(\mathrm{P}>0,05)$ dos níveis de energia metabolizável sobre os pesos de órgãos como coração e pulmões, expressos em $\mathrm{kg}$ e \% (Tabelas 3 e 4). Isso é explicado pelo fato destes órgãos conseguirem manter sua integridade por terem prioridade na utilização de nutrientes, independente do nível de alimentação (FERREIRA et al., 2000). Para o peso dos rins e baço, observou-se efeito significativo $(\mathrm{P}<0,05)$, esses órgãos apresentam elevadas taxas metabólicas, por participar ativamente no metabolismo de nutrientes e, portanto, responde à ingestão de energia (FERREL; JENKINS, 1998a, 1999b). Os resultados desse estudo diferiram dos obtidos por Silva et al. (2002) com bovinos Nelores alimentados com diferentes níveis de concentrado (20; 40; 60 e $80 \%$ ) e proteína ( 15 e $28 \%$ ), bem como os de Alves et al. (2003) em estudos com ovinos da raça Santa Inês alimentados com diferentes níveis de $\operatorname{EM}(2,42 ; 2,66$ e 2,83 Mcal de EM/kg de MS).

Não foi observado influência $(\mathrm{P}>0,05)$ dos níveis energéticos das rações sobre os pesos, em $\mathrm{kg}$ e \%, do CTGI (Tabelas 3 e 4). Resultados diferentes foram obtidos por Gesualdi Junior et al. (2001), alimentando bovinos $\mathrm{F}_{1}$ (Limousin $\mathrm{x}$ Nelore) com cinco níveis de concentrado $(25,0 ; 37,5 ; 50,0 ; 62,5$ e 75,0\%). Assim como Medeiros et al. (2008), que alimentaram ovinos Morada Nova com quatro níveis de concentrado (20; 40; 60 e 80\%). Rações com maiores quantidades de concentrados fornecem maior aporte de nutrientes digestíveis totais, promovendo menor enchimento do trato digestório (BALCH; CAMPLING, 1962; ARC, 1980).

Tabela 3. Médias, coeficiente de variação $(\mathrm{CV})$, coeficiente de determinação $\left(\mathrm{R}^{2}\right)$ e nível de significância $(P)$ para os pesos, em kg, do conteúdo do trato gastrointestinal (CTGI), coração, pulmões, fígado, rins e baço, em função dos níveis de energia metabolizável das rações experimentais.

\begin{tabular}{|c|c|c|c|c|c|c|c|}
\hline \multirow{2}{*}{ Variáveis } & \multicolumn{4}{|c|}{ Níveis de EM (Mcal/kg MS) } & \multirow{2}{*}{$\mathrm{CV}(\%)$} & \multirow{2}{*}{$\mathbf{R}^{2}$} & \multirow{2}{*}{$P$} \\
\hline & 2,08 & 2,28 & 2,47 & 2,69 & & & \\
\hline $\mathrm{CTGI}^{1}$ & 7,92 & 8,15 & 7,37 & 8,44 & 20,73 & - & NS \\
\hline Coração ${ }^{2}$ & 0,089 & 0,106 & 0,113 & 0,101 & 16,63 & - & NS \\
\hline Pulmões ${ }^{3}$ & 0,365 & 0,373 & 0,314 & 0,302 & 27,78 & - & NS \\
\hline Fígado $^{4}$ & 0,316 & 0,403 & 0,490 & 0,516 & 13,51 & 0,99 & 0,0003 \\
\hline Rins $^{5}$ & 0,059 & 0,071 & 0,080 & 0,075 & 8,99 & 0,96 & 0,001 \\
\hline Baço $^{6}$ & 0,037 & 0,045 & 0,061 & 0,056 & 27,38 & 0,72 & 0,028 \\
\hline
\end{tabular}

NS = Não significativo; ${ }^{1} \tilde{Y}=7,97 ;{ }^{2} \tilde{Y}=0,102 ;{ }^{3} \tilde{Y}=0,338 ;{ }^{4} \hat{Y}=-0,358+0,332 \mathrm{EM} ;{ }^{5} \hat{\mathrm{Y}}=-0,555+0,502 \mathrm{EM}-0,099 \mathrm{EM}^{2} ;{ }^{6} \hat{\mathrm{Y}}$ $=-0,034+0,035 \mathrm{EM}$. 
Tabela 4. Médias (\%), coeficiente de variação $(\mathrm{CV})$, coeficiente de determinação $\left(\mathrm{R}^{2}\right)$ e nível de significância $(P)$ para os pesos, em função do peso do corpo vazio (PCVZ), do conteúdo do trato gastrointestinal (CTGI), coração, pulmões, fígado, rins e baço, em função dos níveis de energia metabolizável das rações experimentais.

\begin{tabular}{|c|c|c|c|c|c|c|c|}
\hline \multirow{2}{*}{ Variáveis } & \multicolumn{4}{|c|}{ Níveis de EM (Mcal/kg MS) } & \multirow[t]{2}{*}{ CV $(\%)$} & \multirow{2}{*}{$\mathbf{R}^{2}$} & \multirow{2}{*}{$P$} \\
\hline & 2,08 & 2,28 & 2,47 & 2,69 & & & \\
\hline $\mathrm{CTGI}^{1}$ & 48,30 & 36,07 & 32,07 & 38,87 & 28,22 & - & NS \\
\hline Coração ${ }^{2}$ & 0,52 & 0,46 & 0,50 & 0,46 & 11,30 & - & NS \\
\hline Pulmões ${ }^{3}$ & 2,53 & 1,62 & 1,36 & 1,37 & 27,05 & - & NS \\
\hline Fígado $^{4}$ & 1,91 & 1,78 & 2,13 & 2,31 & 12,02 & 0,77 & 0,001 \\
\hline $\operatorname{Rins}^{5}$ & 0,37 & 0,31 & 0,35 & 0,34 & 14,27 & - & NS \\
\hline Baço $^{6}$ & 0,22 & 0,20 & 0,26 & 0,25 & 22,26 & - & NS \\
\hline
\end{tabular}

NS = Não significativo; ${ }^{\hat{Y}}=38,82 ;{ }^{2} \hat{Y}=0,48 ;{ }^{3} \hat{Y}=1,72 ;{ }^{4} \hat{Y}=0,10+0,80 \mathrm{EM} ;{ }^{;} \hat{Y}=0,34 ;{ }^{\circ} \hat{Y}=0,23$.

$\mathrm{O}$ peso do fígado aumentou linearmente $(\mathrm{P}<0,05)$ em resposta aos nível de energia das rações experimentais. O fígado é importante para os vários processos metabólicos com participação ativa no metabolismo energético e proteico dos animais, a exemplo da captação de cerca de $80 \%$ do propionato que passa pelo sistema portal para a conversão em glicose (VAN SOEST, 1994) e da captação de amônia e conversão em uréia, além do metabolismo de aminoácidos (LOBLEY; MILANO; VAN DER WALT, 2000). À medida que a massa do fígado aumenta, os requisitos energéticos para mantença também se elevam.
Não foi observada influência $(\mathrm{P}>0,05)$ dos níveis energéticos das rações experimentais sobre os pesos, em kg, do rúmen-retículo e omaso (Tabela 5). O crescimento do rúmen-retículo pode ser influenciado por vários fatores, dentre eles a ração (VAN SOEST, 1994). À medida que aumenta os níveis dietéticos de energia, há redução nos teores de fibra em detergente neutro e fibra em detergente ácido, tendo relação direta com o tamanho do rúmen-retículo. Ainda, segundo Van Soest (1994), rações com altos níveis de energia promovem involução do omaso.

Tabela 5. Médias, coeficiente de variação $(\mathrm{CV})$, coeficiente de determinação $\left(\mathrm{R}^{2}\right)$ e nível de significância $(P)$ para os pesos absolutos, em kg, do rúmen-retículo (RURE), omaso (OMA), abomaso (ABO), intestino delgado (ID), intestino grosso (IG) e gorduras perienal (GPR), omental (GO), mesentérica (GM) e do coração (GC), em função dos níveis de energia metabolizável (EM) das rações experimentais.

\begin{tabular}{|c|c|c|c|c|c|c|c|}
\hline \multirow{2}{*}{ Itens } & \multicolumn{4}{|c|}{ Níveis de EM (Mcal/kg MS) } & \multirow{2}{*}{$\mathrm{CV}(\%)$} & \multirow{2}{*}{$\mathbf{R}^{2}$} & \multirow{2}{*}{$P$} \\
\hline & 2,08 & 2,28 & 2,47 & 2,69 & & & \\
\hline RURE $^{1}$ & 0,549 & 0,622 & 0,641 & 0,585 & 12,19 & - & NS \\
\hline $\mathrm{OMA}^{2}$ & 0,060 & 0,065 & 0,066 & 0,056 & 16,49 & - & NS \\
\hline $\mathrm{ABO}^{3}$ & 0,085 & 0,095 & 0,102 & 0,094 & 15,76 & - & NS \\
\hline $\mathrm{ID}^{4}$ & 0,454 & 0,509 & 0,556 & 0,603 & 14,87 & 0,99 & 0,003 \\
\hline $\mathrm{IG}^{5}$ & 0,260 & 0,276 & 0,287 & 0,324 & 11,75 & 0,91 & 0,01 \\
\hline $\mathrm{GPR}^{6}$ & 0,181 & 0,310 & 0,287 & 0,388 & 29,76 & 0,87 & 0,01 \\
\hline $\mathrm{GO}^{7}$ & 0,288 & 0,563 & 0,554 & 0,514 & 36,87 & - & NS \\
\hline $\mathrm{GM}^{8}$ & 0,183 & 0,304 & 0,345 & 0,360 & 29,95 & 0,77 & 0,01 \\
\hline $\mathrm{GC}^{9}$ & 0,49 & 0,73 & 0,78 & 0,33 & 9,36 & 0,94 & 0,01 \\
\hline
\end{tabular}

NS = Não significativo; ${ }^{1} \tilde{Y}=0,599 ;{ }^{2} \tilde{Y}=0,061 ;{ }^{3} \tilde{Y}=0,094 ;{ }^{4} \hat{Y}=-0,049+0,244 \mathrm{EM} ;{ }^{5} \hat{\mathrm{Y}}=0,043+0,102 \mathrm{EM} ;{ }^{6} \hat{\mathrm{Y}}=-0,397+$ $0,290 \mathrm{EM} ;{ }^{7} \tilde{\mathrm{Y}}=0,479 ;{ }^{8} \hat{\mathrm{Y}}=-0,344+0,270 \mathrm{EM} ;{ }^{9} \hat{\mathrm{Y}}=0,223+0,196 \mathrm{EM}-0,041 \mathrm{EM}^{2}$ 
O peso do rúmen-retículo e omaso, expressos em $\%$, apresentou decréscimo linear $(\mathrm{P}<0,05)$ com o aumento dos níveis de EM (Tabela 6). Resultados semelhantes foram obtidos por Silva et al. (2002), porém diferiram dos obtidos por Signoretti et al.
(1999), com bovinos da raça Holandesa alimentados com diferentes relações de concentrado $(45,0 ; 60,0$; 75,0 e $90,0 \%$ ). Rosa et al. (2002), reportaram que o rúmen-retículo e omaso, apresentam crescimento heterogônico tardio ( $\mathrm{b}>1)$, o que contribui para redução do rendimento da carcaça.

Tabela 6. Médias (\%), coeficiente de variação (CV), coeficiente de determinação $\left(\mathrm{R}^{2}\right)$ e nível de significância $(P)$ para os pesos relativos em função do peso do corpo vazio (PCVZ), de rúmen-retículo (RURE), omaso (OMA), abomaso (ABO), intestino delgado (ID), intestino grosso (IG) e gorduras perirenal (GPR), omental (GO), mesentérica (GM) e do coração (GC), em função dos níveis de energia metabolizável (EM) das rações experimentais.

\begin{tabular}{|c|c|c|c|c|c|c|c|}
\hline \multirow{2}{*}{ Itens } & \multicolumn{4}{|c|}{ Níveis de EM (Mcal/kg MS) } & \multirow{2}{*}{$\mathrm{CV}(\%)$} & \multirow{2}{*}{$\mathbf{R}^{2}$} & \multirow{2}{*}{$\boldsymbol{P}$} \\
\hline & 2,08 & 2,28 & 2,47 & 2,69 & & & \\
\hline RURE $^{1}$ & 3,31 & 2,73 & 2,79 & 2,64 & 12,14 & 0,55 & 0,01 \\
\hline $\mathrm{OMA}^{2}$ & 0,37 & 0,29 & 0,29 & 0,25 & 15,65 & 0,78 & 0,002 \\
\hline $\mathrm{ABO}^{3}$ & 0,51 & 0,42 & 0,45 & 0,42 & 15,19 & - & NS \\
\hline $\mathrm{ID}^{4}$ & 2,73 & 2,24 & 2,44 & 2,73 & 17,23 & - & NS \\
\hline $\mathrm{IG}_{5}$ & 1,58 & 1,22 & 1,26 & 1,46 & 15,50 & 0,88 & 0,02 \\
\hline $\mathrm{GPR}^{6}$ & 1,02 & 1,35 & 1,24 & 1,72 & 23,98 & 0,84 & 0,01 \\
\hline $\mathrm{GO}^{7}$ & 1,59 & 2,44 & 2,35 & 2,27 & 37,03 & - & NS \\
\hline $\mathrm{GM}^{8}$ & 1,03 & 1,32 & 1,47 & 1,59 & 27,01 & 0,91 & 0,006 \\
\hline $\mathrm{GC}^{9}$ & 0,29 & 0,32 & 0,34 & 0,15 & 9,36 & 0,92 & 0,04 \\
\hline
\end{tabular}

$\mathrm{NS}=$ Não significativo; ${ }^{1} \hat{\mathrm{Y}}=5,03-0,91 \mathrm{EM} ;{ }^{2} \hat{\mathrm{Y}}=0,69-0,16 \mathrm{EM} ;{ }^{3} \tilde{\mathrm{Y}}=0,45 ;{ }^{4} \tilde{\mathrm{Y}}=2,52 ;{ }^{5} \hat{\mathrm{Y}}=20,92-16,38 \mathrm{EM}+3,40 \mathrm{EM}^{2} ;{ }^{6} \hat{\mathrm{Y}}$ $=-1,01+0,98 \mathrm{EM} ;{ }^{7} \tilde{\mathrm{Y}}=2,16 ;{ }^{8} \hat{\mathrm{Y}}=0,74+0,88 \mathrm{EM} ;{ }^{9} \hat{\mathrm{Y}}=-7,03+6,37 \mathrm{EM}-1,37 \mathrm{EM}^{2}$

O peso do abomaso, expressos em $\mathrm{kg}$ e \%, não foi influenciado $(\mathrm{P}>0,05)$, pelos níveis de energia das rações experimentais. Em relação ao intestino delgado, observou-se influência $(\mathrm{P}<0,05)$ dos níveis de energia sobre esse órgão apenas para o peso expresso em $\mathrm{kg}$. Maior proporção de concentrado promoveu o aumento de comprimento e, conseqüentemente, de peso dessa víscera, provavelmente como forma de ampliar a área de digestão e absorção de nutrientes. Van Soest (1994) reportou que nos ruminantes, somente pequena quantidade de carboidratos solúveis escapa do rúmen para o intestino delgado, e a principal atividade desse compartimento é absorção de aminoácidos. Medeiros (2006) verificou efeito semelhante para o peso, em $\mathrm{kg}$, do intestino delgado, ao alimentar ovinos da raça Morada Nova com quatro níveis de concentrado (20,0; 40,0; 60,0 e 80,0\%). Entretanto,
Alves et al. (2003) não observaram efeito dos níveis de energia metabolizável nas rações sobre o peso do intestino delgado, trabalhando com ovinos da raça Santa Inês com três níveis energéticos $(2,42 ; 2,66$ e 2,83 Mcal de EM/kg de MS).

Já para os pesos, em $\mathrm{kg} \mathrm{e} \%$, do intestino grosso, foi observado efeito linear e quadrático $(\mathrm{P}<0,05)$, respectivamente, com o aumento dos níveis de EM nas rações experimentais. Estes resultados corroboram os obtidos por Ferreira et al. (2000) para o intestino grosso, expressos em $\mathrm{kg} \mathrm{e} \%$, de bovinos $\mathrm{F}_{1}$ (Simental x Nelore) alimentados com cinco níveis de concentrados $(25,0 ; 37,5 ; 50,0$; 62,5 e 75,0\%), mas diferindo de Véras et al. (2001) que não encontraram diferenças significativas para essas variáveis ao alimentar bovinos Nelore com diferentes níveis de concentrados na ração $(25,0$; 32,$5 ; 50,0 ; 62,5$ e $75,0 \%$ ). 
Neste estudo, foi observado efeito significativo $(\mathrm{P}<0,05)$ para os pesos, em $\mathrm{kg}$ e $\%$, das gorduras perirenal, mesentérica e do coração (Tabelas 5 e 6, respectivamente). O aumento do nível de EM nas rações experimentais proporcionou maior quantidade de gordura depositada. Estes resultados corroboram os de Kozloski (2002), afirmando que o aumento de carboidratos solúveis promove aumento na concentração de propionato e diminuição na relação acetato:propionato, resultando em maior disponibilidade de energia, favorecendo a secreção de insulina e induzindo a lipogênese.

\section{Conclusão}

O aumento dos níveis de energia metabolizável das rações influencia o peso dos órgãos internos de ovinos Santa Inês em crescimento.

\section{Referências}

AGRICULTURAL RESEARCH COUNCIL - ARC. The nutrient requeriments of ruminants livestock. London: Commonwealth agricultural Bureaux, 1980. 351 p.

ALVES, K. S.; CARVALHO, F. F. R.; FERREIRA, M. A.; VÉRAS, A. S. C.; MEDEIROS, A. N.; NASCIMENTO, J. F.; NASCIMENTO, L. R. S.; ANJOS, A. V. A. Níveis de energia em dietas de ovinos Santa Inês: características de carcaça e constituintes corporais. Revista Brasileira de Zootecnia, Viçosa, MG, v. 32, n. 6, p. 1927-1936, 2003. Suplemento 2.

ASSOCIATION OF OFFICIAL ANALYTICAL CHEMISTRY - AOAC. Official Methods of Analysis. 15. ed. Arlington: AOAC International, 1990. 1117 p.

BALCH, G. C.; CAMPLING, R. C. Regulation of voluntary intake in ruminants. Nutrition Abstract Reviews, v. 32, n. 3, p. 669-686, 1962.

FERREIRA, M. A.; VALADARES FILHO, S. C.; MUNIZ, E. B.; VÉRAS, A. S. C. Características das carcaças, biometria do trato gastrintestinal, tamanho dos órgãos internos e conteúdo gastrintestinal de bovinos F1 Simental x Nelore alimentados com dietas contendo vários níveis de concentrado. Revista Brasileira de Zootecnia, Viçosa, MG, v. 29, n. 4, p. 1174-1182, 2000.

FERREL, C. L.; JENKINS, T. G. Body composition and energy utilization by steers of diverse genotypes fed a high concentrate diet during the finishing period: II. Angus, Boran, Brahman, Hereford, and Tuli Sires. Journal of Animal Science, Madison, v. 76, n. 2, p. 647657, 1998b.

Body composition and energy utilization by steers of diverse genotypes fed a high-concentrate diet during the finishing period: I. Angus, Belgian Blue, Hereford, and Piemontese Sires. Journal of Animal Science, Madison, v. 76, n. 2, p. 637-646, 1998a.

GESUALDI JÚNIOR, A.; VELOSO, C. M.; PAULINO, M. F.; VALADARES FILHO, S. C.; GESUALDI, A. C. L. S.; CECON, P. R. Níveis de concentrado na dieta de bovinos F1 Limousin x Nelore: Peso dos órgãos internos e trato digestivo. Revista Brasileira de Zootecnia, Viçosa, MG, v. 30, n. 6, p. 1866-1871, 2001.

HALL, M. B. Calculation of non-structural carbohydrate content of feeds that contain non-protein nitrogen. Gainesville: University of Florida, 2000. p. 25 (Bulletin, 339).

KOZLOSKI, G. V. Bioquímica dos ruminantes. Santa Maria: Universidade Federal de Santa Maria, 2002. 140 p.

LOBLEY, G. E.; MILANO, G. D.; VAN DER WALT, J. G. The liver: integrator of nitrogen metabolism. In: CRONJÉ, P. B.; BOOMKER, E. A.; HENNING, P. H. (Ed.). Ruminant physiology: digestion, metabolism, growth and reproduction. London: CAB International, 2000. p. 149-168.

MEDEIROS, G. R.; CARVALHO, F. F. R.; FERREIRA, M. A.; ALVES, K.S.; MATTOS, C. W.; SARAIVA, T. A.; NASCIMENTO, J. F. Efeito dos níveis de concentrado sobre os oponentes não-carcaça de ovinos Morada Nova em confinamento. Revista Brasileira de Zootecnia, Viçosa, MG, v. 37, n. 6, p. 1063-1071, 2008.

MEDEIROS, G. R. Efeito dos niveis de concentrado sobre o desempenho, características de carcaça e componentes não carcaça de ovinos Morada Nova em confinamento. 2006. Tese (Doutorado em Zootecnia) Departamento de Zootecnia. Universidade Federal Rural de Pernambuco, Recife.

MOLETTA, J. L.; RESTLE, J. Características de carcaça de novilhos de diferentes grupos genéticos terminados em confinamento. Revista Brasileira de Zootecnia, Viçosa, MG, v. 25, n. 5, p. 876-887, 1996.

NATIONAL RESEARCH COUNCIL - NRC. Nutrient requirements of sheep. Washington, DC: National Academy Press, 1985. p. 99.

OWENS, F. N.; DUBESKI, P.; HANSON, C. F. Factors that alter the growth and development of ruminants. $J$. Anim. Sci., Madison, v. 71, n. 12, p. 3138-3150. 
PATTERSON, D. C.; YAN, T.; GORDON, F. J.; KILPATRICK, D. J. Effects of bacterial innoculation of unwilted and wilted grass silages. 2. Intake, performance and eating behaviour by dairy cattle. Journal of Agricultural Science, México, v. 131, n. 1, p.113-119. 1998.

ROSA, G. T.; PIRES, C. C.; SILVA, J. H. S.; MOTTA, O. S. Proporções e coeficientes de crescimento dos nãocomponentes da carcaça de cordeiros e cordeiras em diferentes métodos de alimentação. Revista Brasileira de Zootecnia, Viçosa, MG, v. 31, n. 6, p. 2290-2298, 2002.

SIGNORETTI, R. D.; ARAÚJO, G. G. L.; COELHO DA SILVA, J. F.; VALADARES FILHO, S. C.; CECON, P. R.; FERREIRA, M. A. Características qualitativas das partes do corpo não-integrante da carcaça animal e desenvolvimento do trato gastrintestinal de bezerros da raça Holandesa alimentados com dietas contendo quatro níveis de concentrado. Revista Brasileira de Zootecnia, Viçosa, MG, v. 28, n. 4, p. 875-882, 1999.

SILVA, F. F.; VALADARES FILHO, S. C.; ÍTAVO, L. C. V.; VELOSO, C. M.; PAULINO, M. F.; VALADARES, R. F. D.; CECON, P. R.; SILVA, P. A.; GALVÃO, R. M. Consumo, desempenho, características de carcaça e biometria do trato gastrintestinal e dos órgãos internos de novilhos Nelore recebendo dietas com diferentes níveis de concentrado e proteína. Revista Brasileira de Zootecnia, Viçosa, MG, v. 31, n. 4, p. 1849-1864, 2002.

SNIFFEN, C. J.; O'CONNOR, J. D.; VAN SOEST, P. J.; FOX, D. G.; RUSSELL, J. B. A net carbohydrate and protein system for evaluating cattle diets: II. Carbohydrate and protein availability. Journal of Animal Science, Madison, v. 70, n. 10, p. 3562-3577, 1992.
UNIVERSIDADE FEDERAL DE VIÇOSA - UFV. Sistema para análises estatísticas - SAEG. Versão 9.1. Viçosa, MG, 2007.

VAN SOEST, J. P.; ROBERTSON, J. B. Systems of analysis for evaluating fibrous feed. In: PIGDEN, W. J.; BALCH, C. C.; GRAHAM, M. (Ed.). Standardization of analytical methodology for feeds. Ottawa: International Development Research Center, 1980. p. 49-60.

VAN SOEST, P. J. Nutritional ecology of the ruminant. 2. ed. Ithaca: Comstock Publishing Associates, 1994. 476 p.

VAN SOEST, P. J.; ROBERTSON, J. B.; LEWIS, B. A. Symposium: carbohydrate methodology, metabolism, and nutritional implications in dairy cattle. Journal of Dairy Science, Madison, v. 74, n. 10, p. 3583-3597, 1991.

VÉRAS, A. S.; VALADARES FILHO, S. C.; COELHO Da SILVA, J. F.; PAULINO, M. F.; CECON, P. R.; VALADARES, R. F. D.; FERREIRA, M. A.; FONTES, C. M. S. Efeito do nível de concentrado sobre o peso dos órgãos internos e do conteúdo gastrintestinal de bovinos nelore não-castrados. Revista Brasileira de Zootecnia, Viçosa, MG, v. 30, n. 3, p. 1120-1126, 2001. Suplemento 1.

WEISS, W. P. Energy prediction equations for ruminant feeds. In: CORNELL NUTRITION CONFERENCE FOR FEED MANUFACTURERS, 61., 1999, Ithaca. Proceedings... Ithaca: Cornell University, 1999. p. 176. 
